\author{
Elena MEDVEDEVA \\ Sergey KROSHILIN ${ }^{2}$ \\ Elena SLABON ${ }^{3}$
}

\title{
THE ROLE OF COMMUNICATION IN THE FORMATION OF YOUNG PEOPLE'S SOCIAL CAPITAL IN THE CONTEXT OF THE COVID-19 PANDEMIC
}

Introduction: Our society faces new challenges nowadays. The widespread usage of mobile communications and its availability attracts more and more users to the worldwide network. The current generation is unable to isolate themselves from their internet connected gadgets. Clearly, the world is becoming more and more digital and dependent on information and communication technology (ICT). On the one hand, it gives the opportunity to communicate and removes all borders between cities and even continents. On the other hand, youth over-dependence on technology could lead to impaired consciousness, change in mental processes, and the problems of the Googlization of our society. The formation of young people's social capital in the modern society is influenced by information and communication technology and new communication possibilities. Notably, the transformation of communication processes was caused not only by the common availability of communication means and constantly growing network coverage areas, but also by the availability of social networks as the main means of communication among youngsters. Due to the COVID-19 pandemic and self-isolation, communication between young people has become even more dependent on ICT. The means and ways of the formation of human and social capital have also changed.

Aim: The main aim of the research is the evaluation of the influence of information and communication technology on the formation of social capital of young people, as well as the

\footnotetext{
${ }^{1}$ Elena I. Medvedeva, doctor of Economics, Associate Professor, Leading Researcher of the Behavioral Economics Research Laboratory, Institute of Socio-Economic Problems of Population of the Federal Research Center of the Russian Academy of Sciences, 32 NakhimovskyProspekt, Moscow, Russian Federation, 117218; e-mail: e_lenam@mail.ru (corresponding author). ORCID: 0000-0003-4200-1047; Researcher ID B-8964-2018.

${ }^{2}$ Sergey V. Kroshilin, PhD in Technical Sciences, Associate Professor, Senior Researcher at the Behavioral Economics Research Laboratory, Institute of Socio-Economic Problems of Population of the Russian Academy of Sciences, 32 NakhimovskyProspekt, Moscow, Russian Federation, 117218, e-mail: krosh_sergey@mail.ru. ORCID: 0000-0002-6070-1234; Researcher ID J-21842018.

${ }^{3}$ Elena V. Slabon, External PhD Candidate, Institute of Socio-Economic Problems of Population of the Federal Research Center of the Russian Academy of Sciences, 32 NakhimovskyProspekt, Moscow, Russian Federation, 117218; e-mail: helena.slabon@gmail.com. ORCID: 0000-00021411-0839; Researcher ID AAV-6894-2021.
} 
study of the amount of time spent on ICT usage for studying versus communication during the COVID-19 pandemic.

Materials and methods: This research was conducted among young people ages 18-38 and involved more than 500 participants (46\% of whom were men and 54\% women), who work or study in small or medium-sized cities, as well as in rural areas in the south east of the Moscow Region (Russia). The survey was conducted in the beginning of 2021 (after Russia lifted its lockdown restrictions). Participants were as follows: $21 \%$ were secondary school students, $35 \%$ were higher education students, $26 \%$ were college students, and $18 \%$ were working youth. The methods used were custom survey, data processing algorithm, and a part of the longitudinal analysis toolbox known as, "The influence of information and communication technology on youth's health".

Results: To compare the research results (based on the custom longitudinal analysis toolbox, which has been used for 10 years in this region), the data for 2020 (before the COVID-19 pandemic) and 2015 were used. The results showed that information and communication technology have become the main means of communication in the modern society during the pandemic, its use pervades all areas, from distant learning to working from home. Also, while modern technology provided more ways of communication even before the pandemic, it also became the main means of communication, especially during the period of hard lockdowns, thereby, helping to preserve and develop social capital. The pandemic also showed the difference in the access to and the usage of ICT by individuals and households. Particularly, people in areas with poor network coverage have a lower possibility of using internet-connected mobile devices. In addition, the percentage of people using information and communication technology for studying has grown up to $76 \%$ during the pandemic. Almost half of the survey participants started communicating with friends using information and communication technology more often during their self-isolation. While $13 \%$ of all participants think it is easier to use ICT to communicate, $90 \%$ of all respondents use social media for communication.

Conclusions: The pandemic triggered the development and wider usage of information and communication technology, which influence the formation of social capital greatly. The digitalization processes that took place before COVID-19 have strengthened information processes. Opportunities for the formation of social capital of young people have changed as they adapted to the pandemic restrictions (and distancing) that was imposed on the society. The consequences of such changes require a special attention and further research. This research represents a kind of iteration on this complex topic, and it should be analyzed further.

Keywords: social capital of young people, information technology, pandemic, socio-economic issues, communication.

\section{INTRODUCTION}

\subsection{Theoretical and historical background}

In the modern society social capital is one of the communication and knowledge incentive mechanisms. The onrush and expansion of the newest internet-based communication technology effectively influence the processes of the creation of new knowledge (Medvedeva, Kroshilin, 2011). It results in qualitative and quantitative changes of the social capital of the whole society. Social networks (internet-based technology) help to widen people's social circles. Internet forums, chats, pages, etc. make it possible to build social networks, and this is especially relevant for the formation of the social capital of the young people. 
A social capital is usually defined as the networks of relationships among people \& the norms of trust and behavior connected with them, that create the mechanism for social interaction. The definition of "social capital" was introduced by P. Bourdieu in 1983 for denoting social relationships that enable a person to exert power on the group or individual who mobilizes the resources (Fukuyama, 1999). In his article "Social Capital and Civil Society" (Fukuyama, 1999) Fukuyama determines different manifestations of social capital through the prism of the concept known as "The radius of trust". The author divides all groups embodying social capital according to "a certain radius of trust, that is, the circle of people among whom cooperative norms are operative". Most scientists say about two meanings of this notion: cognitive - trust, relationships, values, norms, and behavior patterns, and structural - social institutions, networks, associations. A. Portesstates that social capital is fundamentally shaped by structure of relationships within social relationships that benefit individuals and groups (Coleman, 1988).

The concept of social networks in a scientific context was first used by D. Barnes in 1954. It categorizes a social network as follows:

"Every person belongs to a certain circle of friends, these friends in their turn belong to a circle of their friends. Some friends of this person know each other, and some don't. I found it appropriate to denote such social fields as social networks. I see the system of dots and some of them are connected with each other. The dots represent people and the lines that connect these dots show what people interact with each other" (Veselkin, 1976). This concept can fully denote a social network created on the Internet (e.g. Odnoklassniki, Vkontakte, Twitter, Facebook, etc.).

Internet social network represents a resource designed for communication, creating groups, and sharing personal information. A social network target audience are young people up to 34 years old; they represent $66 \%$ of all users (VTsIOM, 2019). According to comScore researches, even ten years ago Russian users were spending more time on social networks than any other people in the world. The average time people spend on social networks is as follows: world (4.5), Russian Federation (9.8), Israel (9.2), Great Britain (7.3), Canada (5.8), Spain (5.0) (Mohamud, 2010).

Thus, by social capital we understand sociological, economic, and political concept, that denotes social networks and their interactions in the society. The development and universal use of modern ICT have an impact on the processes in the society and lead to enlarging existing and prospective social circles. Modern youth and children are more familiar with new technology, IT, and mass media than their elders. They don't have issues with getting used to new communication means, they know computer technology very well, they got used to new ways of searching the information, they are not afraid to use different new gadgets (Medvedeva, Kroshilin, 2013). That is why the formation and development of social capital of the modern youth and older generations is different.

Many young people, teenagers, and even children prefer to communicate in cyberspace via chat, social networks instead of in-person communication. On the one hand, this process helps to widen social circles and removes its borders, but on the other hand, negative consequences of such virtualization still exist (Medvedeva, Kroshilin, 2012). As a result, all the above creates a new culture for network interactions which is based on the usage of modern means of communication. 


\subsection{Modern Statistics}

The main possibilities of communication and receiving and sharing knowledge represent the following numbers: $59 \%$ of the world population is already online $(81 \%$ in Russia), $67 \%$ use mobile phones ( $163 \%$ in Russia, i.e. 1.5 mobile phone per person). $95 \%$ of the world population live in the areas covered by network. Mobile phones make it possible to communicate via the Internet nowadays. More than a half of users $(53.3 \%)$ use the Internet on their mobile phones and almost the same number of users (49\%) use social networks for communication (Picture 1, 2, 3) (Global Digital 2021, 2021).

The development of the Internet technology widens social circles and improves personal social capital at the same time. According to scientists, almost $78 \%$ of young population in Russia use social networks, the number of such people in Japan is $89 \%$, in France $48 \%$, in Germany $57 \%$. The analysis of mobile applications used in Russia and in the world shows, that $92 \%$ of Russians use social networks. This number is $3 \%$ bigger than the number of such people in the world. $87 \%$ of people communicate via chat applications (messengers). This is $2 \%$ less that the number of such people in the world (Picture 2). More than a half of users all around the world $(53.3 \%)$ use their mobile phones to connect to the Internet (Picture 3).

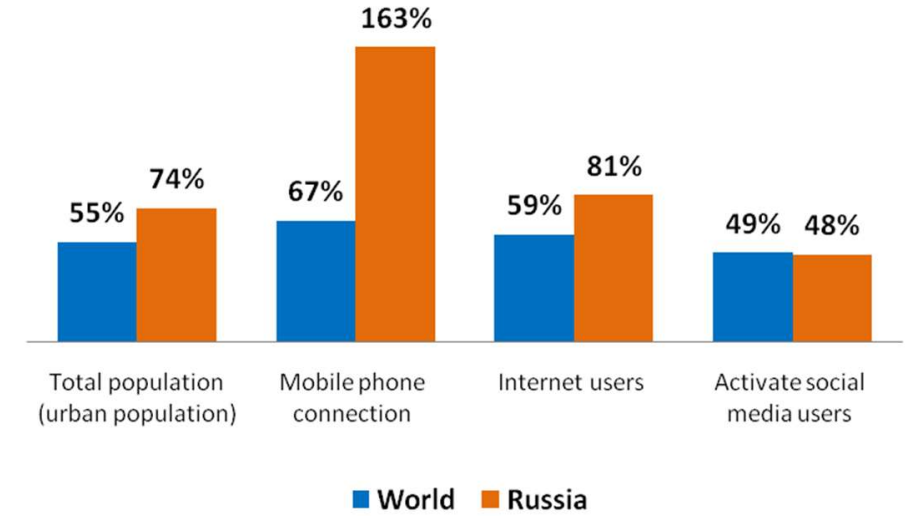

Picture 1. The number of Internet users in Russia and in the world in 2021 (\% of population)

Source: (https://www.web-canape.ru/business/internet-2020-globalnaya-statistika-i-trendy/ [access: 20.03.2021]).

Using mobile internet is obviously convenient. However, there are still some places in the world with no or partial network coverage. The limits or the absence of the internet connection lead to digital inequality. E.g. it could limit children to be online, prevents them from being competitive in the modern society. In case the schools are closed as it happened during the COVID-19 pandemic it leads to the situation when the access to education for such children becomes restricted. 


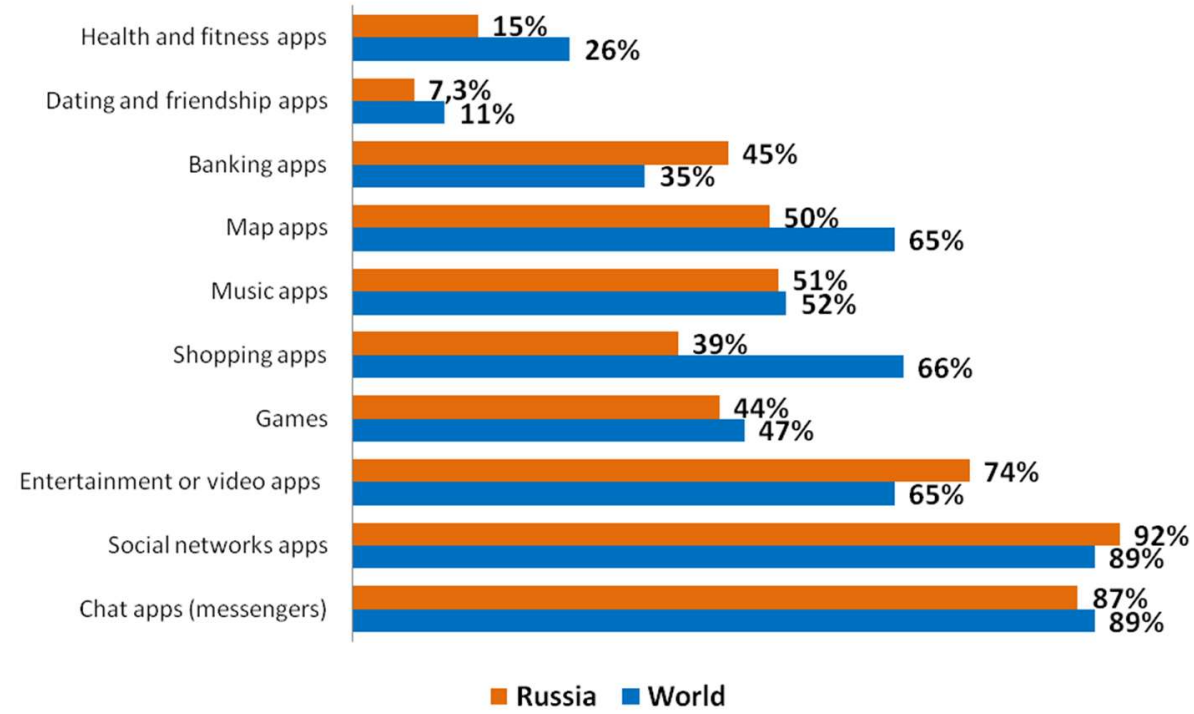

Picture 2. Mobile application in the world and in Russia in 2021

Source: (https://www.web-canape.ru/business/internet-2020-globalnaya-statistika-i-trendy/ [access: 20.03.2021]).

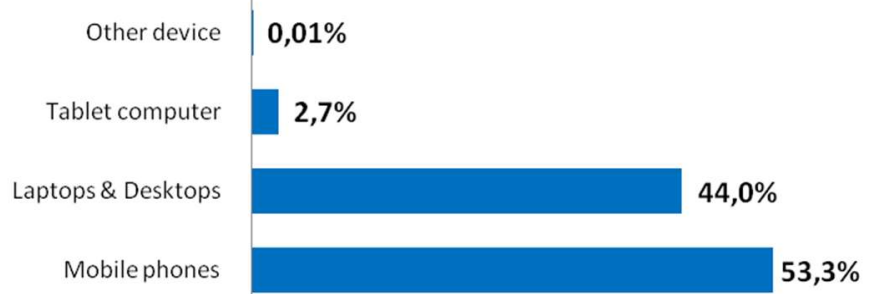

Picture 3. Devices for accessing the Internet in the World in 2021

Source: (https://www.web-canape.ru/business/internet-2020-globalnaya-statistika-i-trendy/ [access: 20.03.2021]).

Two thirds of the world's school-age children - or 1.3 billion children aged 3 to 17 years old - do not have internet connection in their homes, according to a new joint report from UNICEF and the International Telecommunication Union (ITU) (01.01.2020) (Table 1) (UNICEF, 2020).

The lack of internet access will cost a new generation their future. According to UNICEF, the number of school-age children affected by school closures during the COVID19 pandemic has increased by $38 \%$. It made difficult to progress in their education and negatively impacted the well-being of 90 million schoolchildren all over the world. "That so many children and young people have no internet at home is more than a digital gap - it is a digital canyon", said Henrietta Fore, UNICEF Executive Director (UN, 2020). 
Table 1. School-age children without internet connection in their homes, $\%$

\begin{tabular}{|l|c|}
\hline \multicolumn{1}{|c|}{ Region } & $\begin{array}{c}\text { School-age children 3-17 years old } \\
\text { unconnected at home }\end{array}$ \\
\hline West and Central Africa & $95 \%-194$ million \\
\hline East and Southern Africa & $88 \%-191$ million \\
\hline South Asia & $88 \%-449$ million \\
\hline Middle East and North Africa & $75 \%-89$ million \\
\hline Latin America and the Caribbean & $49 \%-74$ million \\
\hline Eastern Europe and Central Asia & $42 \%-36$ million \\
\hline East Asia and the Pacific & $32 \%-183$ million \\
\hline Global & $67 \%-1.3$ billion \\
\hline
\end{tabular}

Source: Two thirds of the world's school-age children have no internet access at home [Electronic resource] // UNICEF [access: 05.05.2021]. Access on the internet: https://news.un.org/ru/story/2020/12/1391572

Nowadays children having no possibility to be online face certain hardships feeling isolated from the rest of the world. In the situation when schools are closed due to the COVID-19 pandemic many young people and children lack the access to primary and secondary education. The people who did not have the possibility to use information and communication technology suffer even more from digital inequality during the pandemic. The digital gap in the society becomes more and more obvious.

About a quarter of a billion school children were affected by school closures during the COVID-19 pandemic to some extent. Hundreds of millions of school children must rely on online education. For those who have no access to the Internet education has become unavailable (UN, 2020).

According to WHO experts, a child could experience the lack of social skills and gain mental health problems in the long run due to kindergartens, schools, and other educational institutions closures. "Childhood and adolescence are crucial periods for neurobiological, behavioral, and social development. Physical distancing measures as well as measures for limiting transmission of COVID-19 reduce the opportunities for children and young people to interact with peers. It could influence their mental health", states V. Poznyak, Addictive Behaviors Specialist in the WHO (Balandina, Safronova, 2020).

In our country the transition to distant and online education went smoothly in comparison to other countries. The availability of hardware and software required for videoconferences confirm only $11 \%$ of all school children in Russia (according to the National Research University Higher School of Economics). While the availability of hardware and software required for audioconferences is confirmed by $21 \%$ of school children in Russia. More than one third of all children surveyed (38\%)can do their homework using online educational platforms.

Firstly, the main problem is low Internet speed which teachers and children from small, medium-sized cities, as well as in rural areas have. Secondly, people with lower income can't change their Internet plan to a better one (e.g. changing a provider, buying unlimited 
Internet package, etc.). Thirdly, some teachers and school children do not have required hardware at home (e.g. computer, web-camera, etc.).

Those children who had to self-isolate during the COVID-19 pandemic lack the ability to interact with their peers, develop their social skills. During quarantine or self-isolation, the ways to gain "support and motivation" are very limited. Obviously, educational institutions help to acquire the most important communication skills. Autonomy in making new friends and acquaintances affects child's future abilities to build relationships and to fulfill themselves in the modern world (Balandina, Safronova, 2020).

\section{AIM}

The main aim of the research is the evaluation of the influence of information and communication technology on the formation of social capital of young people.

The following assumptions have been made:

A1: There are many factors that could influence the formation of social capital of young people nowadays. The COVID-19 pandemic has become a great challenge \& the situation has very much turned around.

A2: The governments of all countries have taken unprecedented measures to prevent the spread of COVID-19. These measures have influenced the development od social and economic processes in our society greatly, i.e. showed the need for distant learning and education. Communication processes have changed as well.

A3: During the COVID-19 pandemic the possibilities of information and communication technology would become the main factor for satisfying the demands of the modern society from the organization of educational process to remote work. It could provide a strong push towards exploring the new ways of training and retraining for a quicker development of skills and professions.

A4: The pandemic has showed a significant digital inequality in our society. The possibility to use mobile phone to connect to the Internet was complicated by poor network coverage in some areas. It made it difficult to communicate, learn \& work remotely.

\section{MATERIALS AND METHODS}

The following tools were used for the research:

1. Customer survey and the data processing algorithm developed by the authors.

2. The part of longitudinal analysis toolbox called "The influence of information and communication technology on youth's health" which has been used for 10 years in this region. The data for 2020 (before the COVID-19 pandemic) and 2015 were used.

Joint studies of the researches from the Institute of Socio-Economic Studies of Population of the Russian Academy of Sciences (Moscow) together with the authors showed that the problem of the formation of social capital of young people during the COVID-19 pandemic is very important and diverse: the process of the formation of social capital of young people is changing. Most of all it relates to the spread and availability of the Internet, as well as to the influence of social, economic, and political factors, ongoing global processes including the COVID-19 pandemic. The development of the Internet technology widens social circles and improves personal social capital at the same time. This issue requires further in-depth study.

A field study was conducted to evaluate the level of the influence of communication and modern technology on the formation of social capital of young people. The survey was 
conducted in the beginning of 2021 (after lifting lockdown restrictions in Russia) and involved more than 500 people: $21 \%$ of secondary school students, $35 \%$ of higher education students, $26 \%$ of college students, $18 \%$ of working youth. The gender distribution was as follows: $46 \%$ of men and $54 \%$ of women. The geographic representation of survey respondents was as follows: small or medium-sized cities (Kolomna, Voskresensk, Egorievsk, Lukhovitsy, Ozyory, Kashira, Stupino, Zaraysk), around 10\% of the respondents live in rural areas in the south east of the Moscow Region (Russia) (Picture 4, 5).

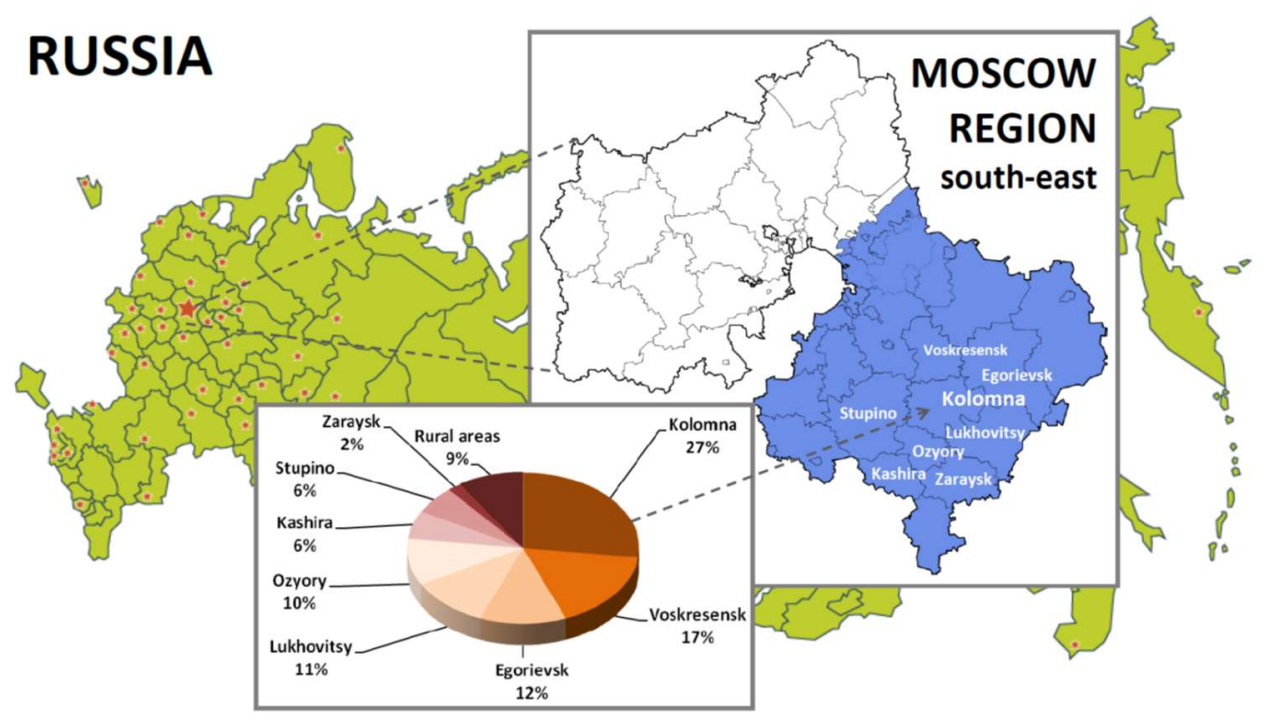

Picture 4. Geographic representation of survey respondents and the number of people surveyed, $\%$

Source: developed by the authors.

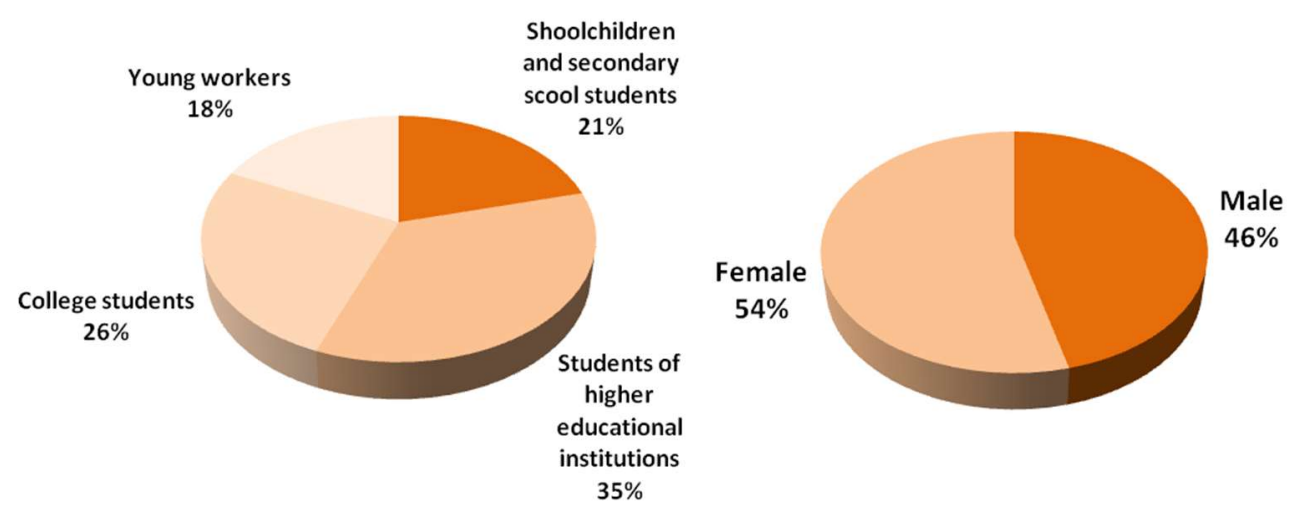

Picture 5. Gender representation of survey respondents and the number of people surveyed, $\%$ Source: developed by the authors. 
The longitudinal analysis research (Medvedeva, Kroshilin, 2011) has been used for 10 years in this region. It allows to compare the research data. The selected areas (by demographic, numerical, gender, and qualitative indicators) are typical for many Russian cities. This helps to extrapolate the research data to other areas for decision-making. The processes coved by this research are more open to the influence of information and communication technology. However, studies there could be more representative across Russia, due to a huge difference in educational, working, and financial opportunities young people have in large cities and rural areas. Quota sampling method was used to target the data based on the required population size and composition. All this enable to approximate the results across the country.

\section{RESULTS}

\subsection{Learning and education}

First, we assed learning possibilities during the COVID-19 pandemic. Russian higher education system has proved itself and its effectiveness under pressure. $96 \%$ of all higher educational institutions in Russia completed the 2020 academic year remotely. Under these circumstances, many educational institutions had to use all possible means for remote learning (Kroshilin, Dobrokhleb, 2018). The diversity of information and communication technology specially designed for education was in high demand. The tool choice was regulated by the demand of certain Ministries. Schools and colleges decided to use online platform "School Portal", higher educational institutions used their own online learning platforms as well as platforms for online teaching (Zoom, Skype, etc.) (Kroshilin, Dobrokhleb, 2018). Many teachers were not familiar with these tools and technology.

According to the data from the expert analytical research, which were presented during the meeting of the Public Council at the Ministry of Education and Science (in 2019) around $60 \%$ of teaches have rarely or never given lectures and lessons remotely or in webinar format. They rated their knowledge of cloud technologies as 3.5 of 5 points. $88 \%$ prefer traditional face-to-face learning. Teachers did not consider traditional face-to-face learning to be fully substituted by distant learning. They believe there is a number of risks related to students' motivation \& deprofessionalization of teachers in the active development of digital learning technologies ("Stress-tests" Lessons, 2020):

- $65 \%$ of teachers believe they are not able to control student engagement in the process during remote lectures,

- more than $70 \%$ were afraid of cheating in exams,

- $60 \%$ of teachers were unsure of the quality of remote education.

However, about $95 \%$ of students had to begin remote or hybrid education within several weeks in 2020. Almost all Russian higher educational institutions were ready to work in a new environment. This readiness helped to retain a sense of stability among teachers and students. The majority of courses took place according to the schedule and were not rescheduled for other semesters. The COVID-19 pandemic clearly showed the diversity among higher educational institutions and potential risk of further inequality: $20 \%$ of higher education institutions were working in hybrid mode, $60 \%$ changed for remote learning with a lower quality of education, $20 \%$ went for distant learning without paying attention to the quality of education, $15 \%$ "lost" their students, as there was no online tool to communicate with students during the first 2-3 weeks (First Weeks Storm, HSE, 2020). 
The problem of unequal access to quality educational resources has become topical (Medvedeva, 2013; Medvedeva, Kroshilin, 2014): 13\% of higher educational institutions were not even minimally equipped, only $11 \%$ of higher educational institutions have digital infrastructure, one third of students with low income did not have hardware required for remote learning. Universities remote learning experience also showed that efficient use of such technologies requires special knowledge from teachers, managers, students. It also showed the requirement for effective and convenient technological solutions, as well as a special organization of education process. This situation has proved that some very important processes within universities can't be digitized or moved to cyberspace. The reality showed that it's not possible to fully implement higher educational program remotely ("Stress-tests" Lessons, 2020).

Students had an overall positive assessment of remote education: $34 \%$ of students do not consider remote education less effective, $55 \%$ of students were less tired from learning, one third os students preferred distant learning to traditional face-to-face learning, 49\% believed they have more free time, $64 \%$ admitted they sleep longer. However, remote education has also negative effects: more than $40 \%$ of students noticed an increase in their study load (especially in self-study), the same percentage of students consider the lack of communication with teachers and peers as the most challenging during distant learning. $39 \%$ see difficulties in studying at home $35 \%$ find it difficult to ask questions to their teacher online, $33 \%$ of students are confused and embarrassed when being asked to switch their web camera on) (First Weeks Storm, HSE, 2020).

According to our researches, the shift to remote learning required not only the use of desktop computers, but also the use of mobile devices, especially mobile phones (smartphones). During remote learning students were using all available devices (Picture 6).

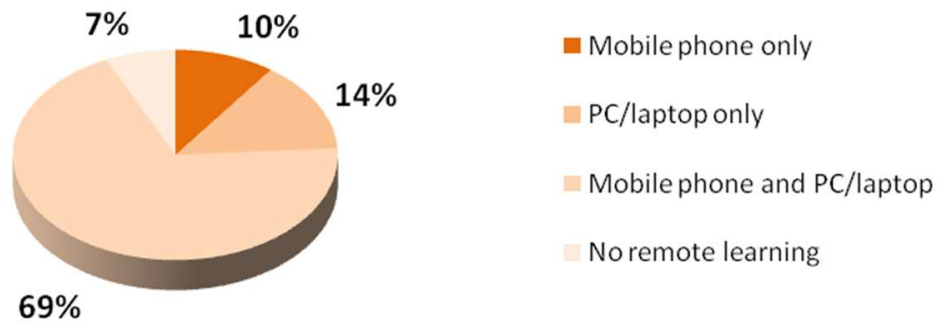

Picture 6. Devices used for remote learning, \%

Source: developed by the authors.

$69 \%$ of all respondents used their mobile phone and PC (laptop) for remote learning, $10 \%$ used only their mobile phone, and $14 \%$ used only a PC (laptop). $15 \%$ of all respondents noticed the increase in their expenses for mobile \& internet connection, however, these expenses remained unchanged for $80 \%$ of all respondents (mostly for those who had unlimited Internet packages)

The degree of credibility to information and communication technology has grown during the COVID-19 pandemic (Picture 7). 
a 2021 during the COVID-19 pandemic $\quad 2020$ before the COVID-19 pandemic $\quad 2015$

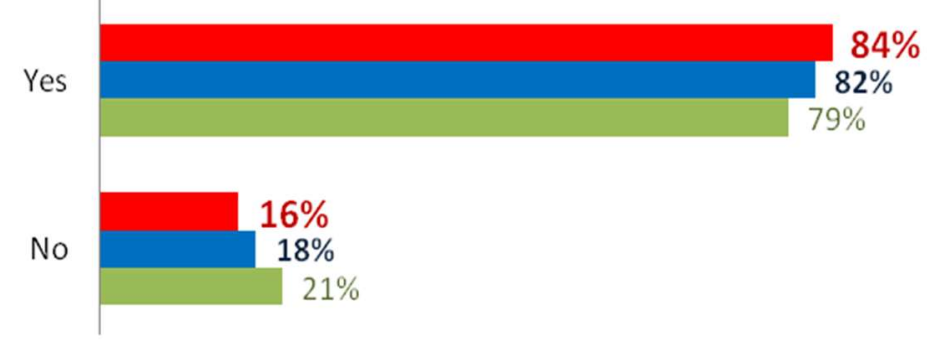

Picture 7. Answers to the survey question "Does information and communication technology make quality education more available?", \%

Source: developed by the authors.

$84 \%$ of respondents are sure that the use of information and communication technology make quality education more available. $64 \%$ of respondents became active users of education portals, while only $46 \%$ of them had known about such portals before the COVID-19 pandemic (Picture 8).

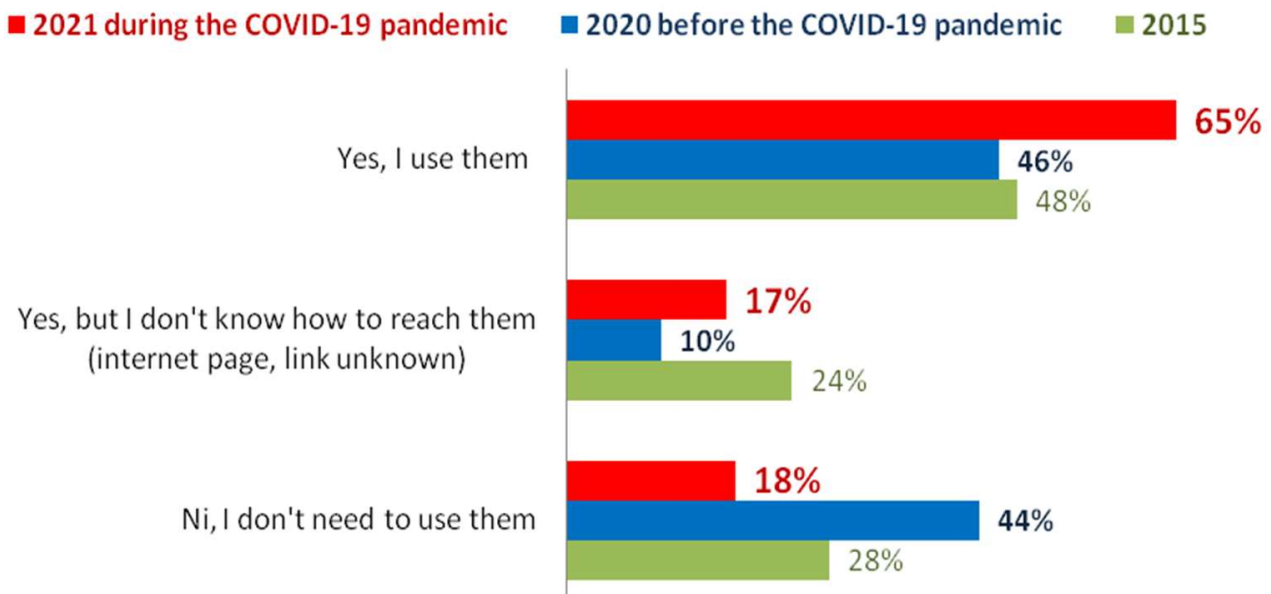

Picture 8. Answers to the survey question "Do you know about the existence of education portals on the Internet?", \%

Source: developed by the authors

Five years ago, almost one third of respondents had no idea of the existence of education portals on the Internet, and almost one fourth of respondents $(24 \%)$ did not know how to reach them. Nowadays (with the help of remote learning) it makes no difference for almost 
half of respondents what version to read (paper or electronic). The number of people who prefer to use paper version has decreased to $34 \%$ (compared to $2020-44 \%, 2015-47 \%$ ) (Picture 9).

- 2021 during the COVID-19 pandemic $\quad 2020$ before the COVID-19 pandemic $\quad 2015$

Paper version (books, magazines, printouts, ect.)
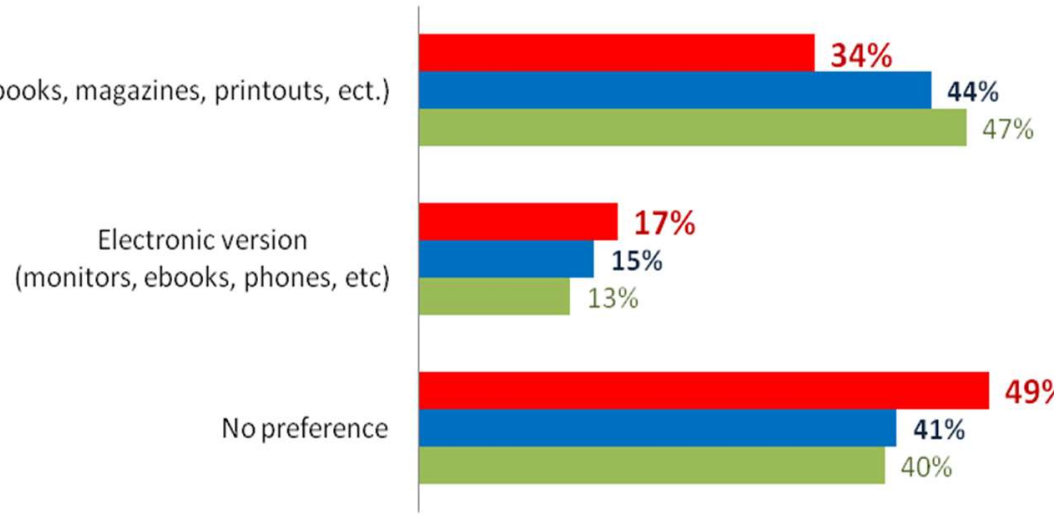

Picture 9. Answers to the survey question "What version do you prefer to read, paper or electronic?", \%

Source: developed by the authors.

Young people confidence in the fact information and internet technologies can provide a required level of knowledge instead of just information has led to the "Googlization" concept (Medvedeva, Kroshilin, 2014). The surveyed believe, that all information and knowledge could be found on the Internet without making any effort. Yandex motto "Find everything!" has become the designated panacea for managing any task or even any life issue. Typing an unknown term in search bar is becoming the only way to acquire new knowledge for many people.

$89 \%$ of respondents use search bar in their browser (Yandex, Google, etc) when they need to check the meaning of any new term or concept, in 2020 the number of such people was equal to $84 \%(81 \%$ in 2015$)$. Only $4 \%$ prefer to ask their tutors or teachers, $5 \%$ of respondents ask their friends. Only a few of respondents go to the library (Picture 10).

In the situations when people have to learn something new or would like to get an answer to any problem, they prefer to use the Internet. Modern generation becomes more and more addicted to communication technology and the possibility to be online all the time. Answering the question "Would your life change if you are no longer able to use the Internet?" $58 \%$ of respondents replied that their life would change a lot. In 2020 before the COVID-19 pandemic only $48 \%$ of respondents responded the same way, in 2015 the number of such respondents was $42 \%$ (Picture 11 ). 
Use search bar in their browser (Yandex, Google, etc)

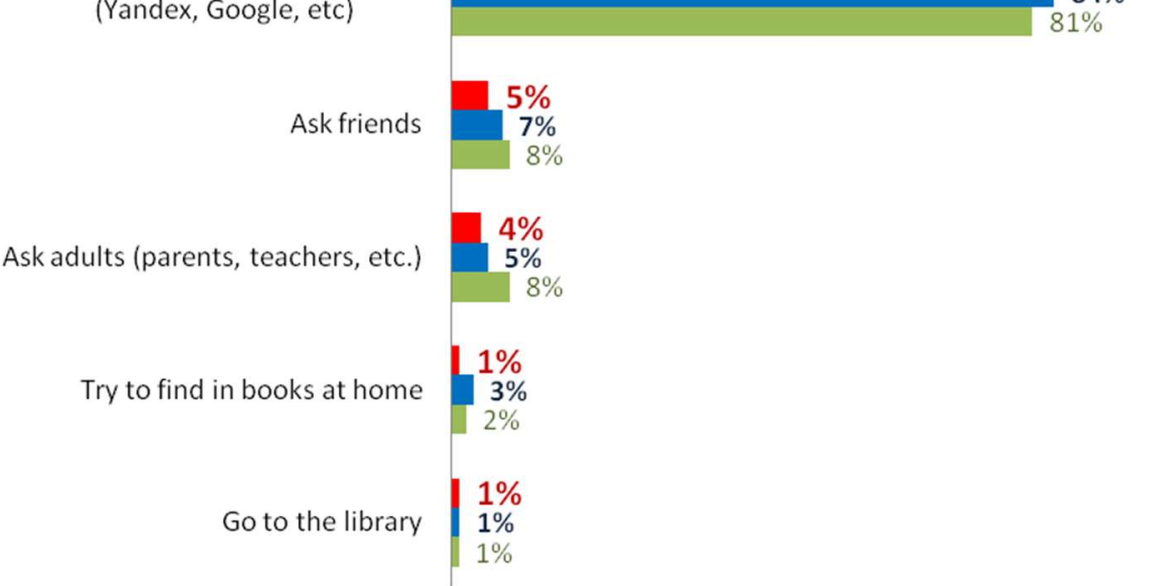

Picture 10. Answers to the survey question "What would you do if you come across the term or concept you are not familiar with?", \%

Source: developed by the authors.

- 2021 during the COVID-19 pandemic $\quad 2020$ before the COVID-19 pandemic $\quad 2015$

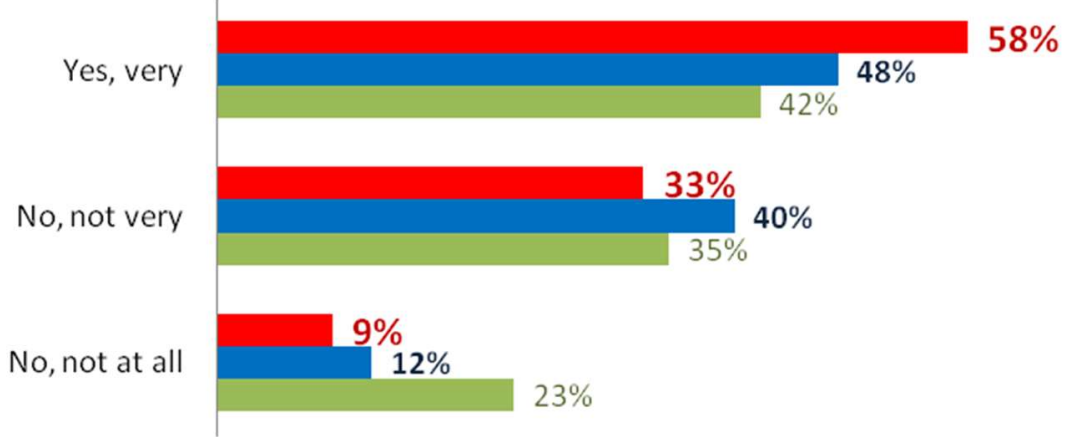

Picture 11. Answers to the survey question "Would your life change if you are no longer able to use the Internet", \%

Source: developed by the authors. 


\subsection{Communication and social capital}

Nowadays people use the Internet mostly to communicate (almost 90\%) (Picture 12).

- 2021 during the COVID-19 pandemic

घ 2020 before the COVID-19 pandemic $\quad 2015$

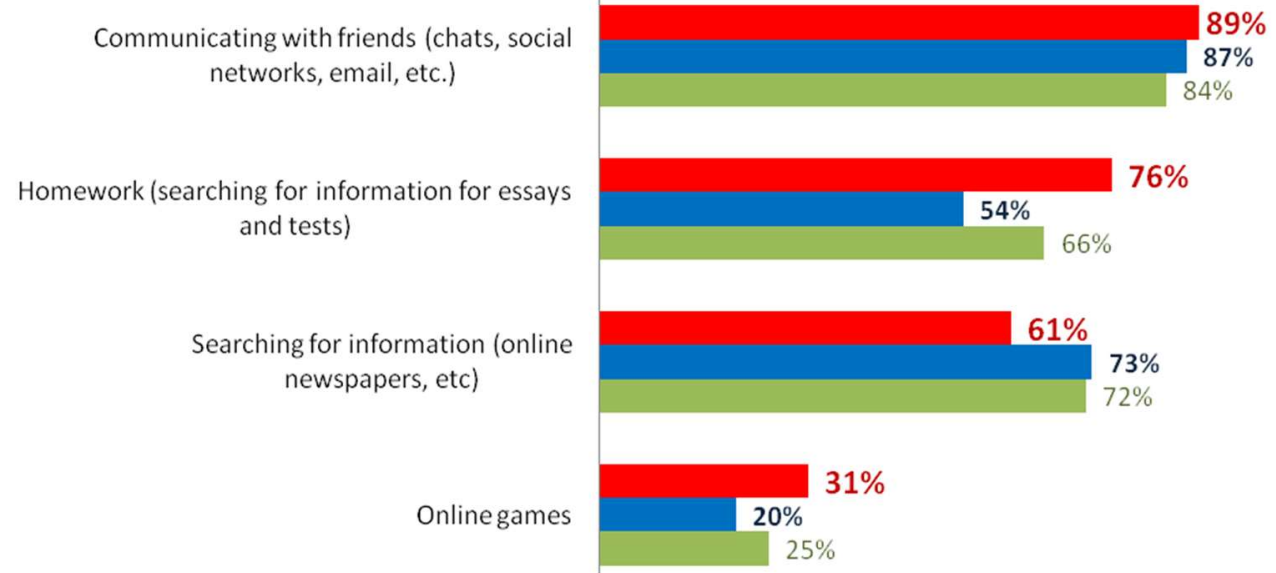

Picture 12. Top uses of the Internet, \%

Source: developed by the authors.

The number of people who use the Internet for doing homework (searching for information for essays and theses) has increased and is $76 \%$ in 2021, in 2020 before the COVID-19 pandemic the number of such people was $54 \%$.

$42 \%$ of respondents told they started communication more with their friends using communication technology during the COVID-19 pandemic, $40 \%$ of respondents claimed their time spent on communication technology didn't change. $47 \%$ of respondents told they spent on communication technology 3 or more hours, that makes it two times longer than in $2020.23 \%$ of respondents spent all their free time on communication technology, while in 2020 and 2015 the number of respondents responded the same way was $23 \%$ and $15 \%$ respectively. $17 \%$ of respondents said their social circles expanded during the COVID-19 pandemic. $19 \%$ of respondents, however, claimed that their social circles became smaller. $61 \%$ of respondents confirmed their social circles remained the same (Picture 13, 14, 15).

Answering the question "Would you prefer to communicate face-to-face or with the help of communication technology?" In 2021 13\% of respondents replied that it's easier for them to communicate using communication technology $(10 \%$ in 2020$)$. The number of respondents who prefer face-to-face communication has decreased by $10 \%$ from $53 \%$ in 2015 and to $43 \%$ in 2021 (Picture 16).

$90 \%$ of respondents use messengers for communication ( $73 \%$ in 2020$)$. Less people call via mobile phones $-52 \%$ ( $80 \%$ in 2020$)$. Emails are becoming increasingly rare; however, people communicate via video calls more often (39\% in 2021) (Picture 17). 
$3 \%$

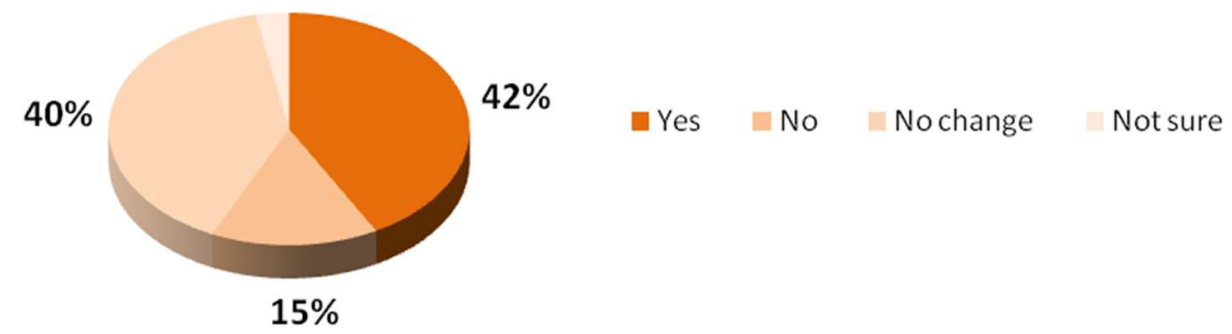

Picture 13. Answers to the survey question "Have you started communicating with your friends using communication technology more often during the COVID-19 pandemic (self-isolation)?", \%

Source: developed by the authors.

- 2021 during the COVID-19 pandemic $\quad 2020$ before the COVID-19 pandemic $\quad 2015$

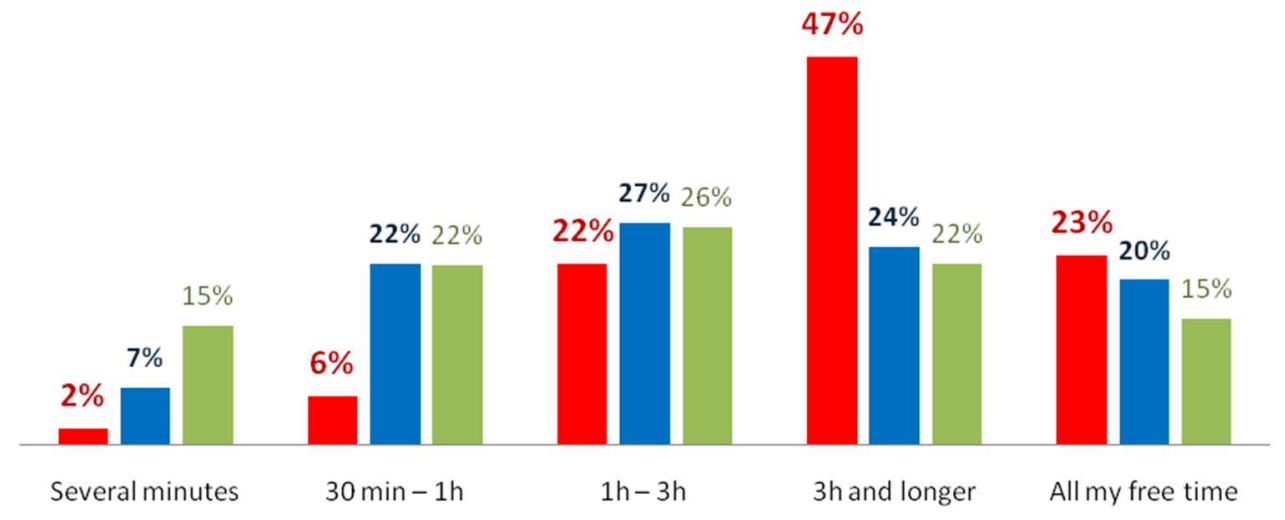

Picture 14. Answers to the survey question "How much time approximately did you spend on communication with your friends using communication technology (messengers, emails, video calls, etc.)?"

Source: developed by the authors.

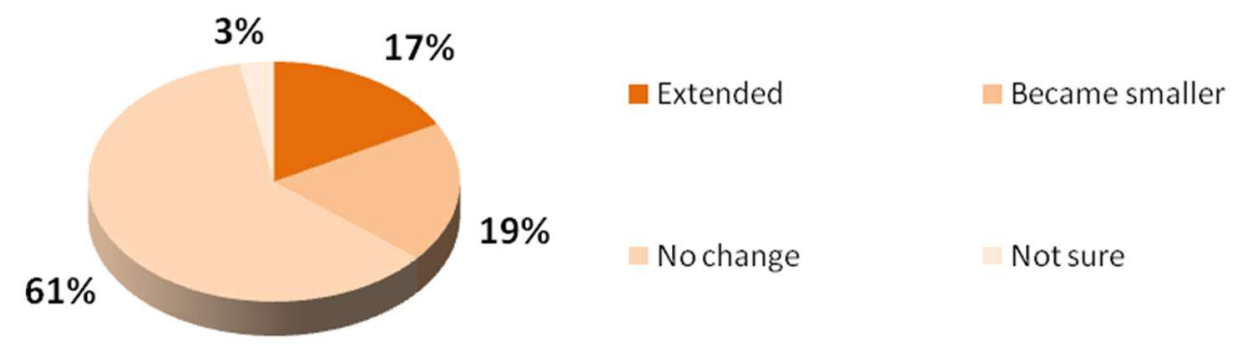

Picture 15. Answers to the survey question "Has your social circle changed due to the COVID-19 pandemic (self-isolation)?", \%

Source: developed by the authors. 
- 2021 during the COVID-19 pandemic

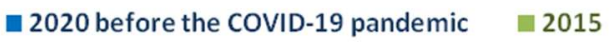

Yes, I prefer to communicate face-to-face

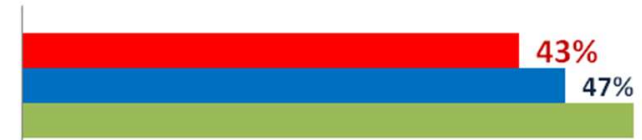

No, I prefer to communicate using modern ICT

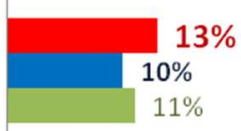

No preference

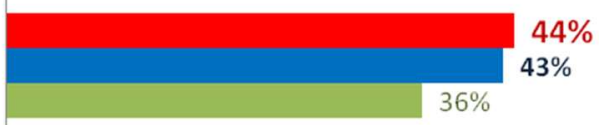

Picture 16. Answers to the survey question "Would you prefer to communicate face-to-face or with the help of communication technology?", \%

Source: developed by the authors.

2021 during the COVID-19 pandemic

2020 before the COVID-19 pandemic

2015

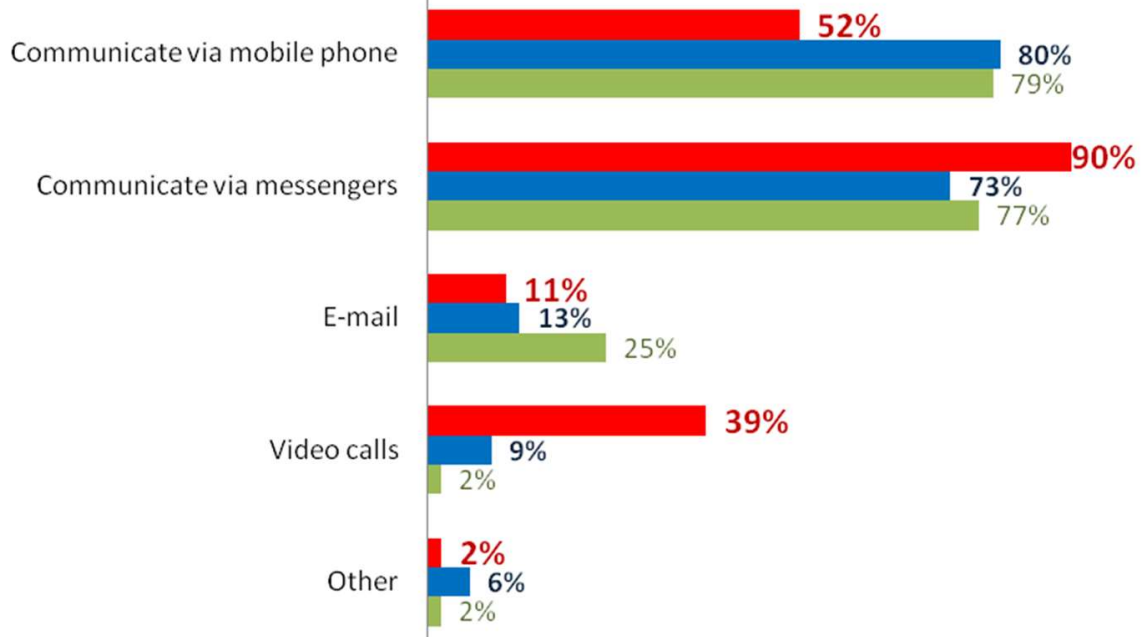

Picture 17. Answers to the survey question "What modern communication technology do you use for communication with your friends?", $\%$

Source: developed by the authors.

According to the research, respondents started to spend more time on social networks. $40 \%$ of respondents spend 3 or more hours on social networks ( $26 \%$ in 2020$) .17 \%$ of respondents spend all their free time on social networks, while in 2020 the number of such people was $10 \%$ only (Picture 18). 
- 2021 during the COVID-19 pandemic $\quad 2020$ before the COVID-19 pandemic $\quad 2015$

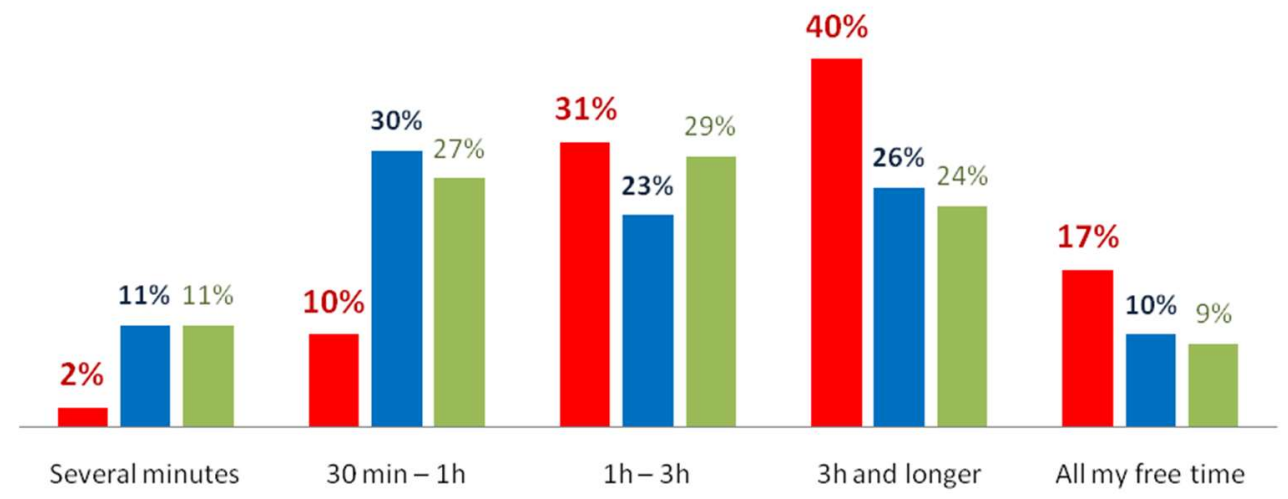

Picture 18. Answers to the survey question "How much time a day you spend on social networks?", \%

Source: developed by the authors.

The preferences of Russian young people regarding social networks haven't changed. $93 \%$ of respondents use Vkontakte, $60 \%$ use WhatsApp, $22 \%$ use recently popularTikTok, Twitter and Facebook are used by significantly less amount of people $-8 \%$ and $7 \%$ respectively.

\section{DISCUSSION}

It goes without saying, that there are several factors from geographical and demographic to social and economic that influence social capital nowadays. The COVID-19 pandemic has become a great challenge. Unprecedented measures taken to prevent the spread of COVID-19have influenced the development and social and economic processes in our society greatly. The world has faced the need for distant learning for the first time. Education process itself has changed as well as communication processes in our society.

The following conclusions may be drawn based on the results of the research:

1. We can conclude with a high degree of probability that during the COVID-19 pandemic the possibilities of information and communication technology have become the main factor for satisfying the demands of the modern society from the organization of educational process to remote work. Modern technology provided more ways of communication even before the pandemic, but also became the main means of communication especially during the period of hard lockdowns, helping to preserve and develop social capital. All these new possibilities, i.e. getting information and knowledge, cannot be overstated. It could provide a strong push towards exploring the new ways of training and retraining for a quicker development of skills and professions.

2. The pandemic has showed a significant digital inequality in our society. Despite of its widespread and better availability, advanced information technology requires significant financial investments in the very beginning (hardware purchase, installation, training, etc.) as well as later (Internet packages, speed upgrade, etc.). 
The possibility to use mobile phone to connect to the Internet was complicated by poor network coverage in some areas. It made it difficult to communicate, learn \& work remotely.

3. The Internet is mostly used for communication nowadays (90\% of respondents). The percentage of people using information and communication technology for studying has grown up to $76 \%$ during the pandemic. $42 \%$ of respondents told that communication technology was the only way to communicate with their friends during the COVID-19 pandemic (self-isolation). $47 \%$ of respondents told they spent on communication technology 3 or more hours, that makes it two times longer than in 2020. $17 \%$ of respondents said their social circles expanded during the COVID-19 pandemic. $13 \%$ of respondents replied that it's easier for them to communicate using communication technology. $90 \%$ of respondents use messengers for communication \& $40 \%$ of respondents spend 3 or more hours on social networks (26\% in 2020). $17 \%$ of respondents spend all their free time on social networks, while in 2020 the number of such people was $10 \%$ only.

It is therefore possible to speak about a new format of the development of social capital of young people influenced by external changes (the COVID-19 pandemic) and modern possibilities of information and communication technology.

\section{CONCLUSION}

According to the research results, we can conclude that our society is constantly changing. The pandemic has provided a strong push towards development and application of information and communication technology, that in its turn influenced the formation of social capital greatly. The digitalization processes that took place before COVID-19 have strengthened their influence on all information processes. The nature of the opportunities for the formation of social capital of young people has changed. The elements of distantness appeared in almost all areas of life due to the pandemic restrictions the society had to align to. The consequences of such changes require a special attention and further research. The research represents a kind of iteration regarding this topic, as the issue is complex, has many aspects, and should be analyzed further.

\section{REFERENCES}

Balandina, A. Safronova, E. (2020. Kindergarten in Lockdown: the Lack of Communication and its Influence on Children [access: 05.05.2021]. Access on the internet: https://www. gazeta.ru/social/2020/12/13/13398133.shtml

Bromley, Y. (1976). The Concept of a Social Network in British Social Anthropology. W Y. Bromley, Foreign Anthropology Concepts (p. 125-152). Moscow: Nauka.

Coleman, J. (1988). Social Capital in the Creation of Human Capital. "American Journal of Sociology Supplement" 94.

Dobrokhleb, V. K. (2018). Continues Education in Russia as One of Factors of Economic Growth. Collective Monograph - 273. Kolomna: The Institute of Socio-Economic Studies of Population RAS, The State University of Social Sciences and Humanities Kolomna.

First Weeks Storm: the Way Higher Education Entered the COVID-19 Pandemic (2020). 6(36). Modern Education Analytics, HSE [access: 05.05.2021]. Access on the internet: https://ioe.hse.ru/data/2020/05/26/1551527214/CAO\%206(36) 
Fukuyama, F. (1999). Social Capital and Civil Society The Institute of Public Policy. Fairfax: George Mason University.

Initiative of Russian Ministry of Education. (2020). "Stress-tests" Lessons. Higher Educational Institutions during the COVID-19 Pandemic and After It: Analytical report [access: 05.05.2021]. Access on the internet: https://www.hse.ru/data/2020/07/06/1595281277/003_ Доклад.pdf

Kroshilin, S., Dobrokhleb, V. (ed.) (2018). Continues Education in Russia as One of Factors of Economic Growth. The Institute of Socio-Economic Studies of Population RAS, The State University of Social Sciences and Humanities Kolomna.

Medvedeva, E. (2013). The Restructuring of Education Under Conditions of the Innovative Development of the Economy. "Russian Education and Society", 55(11).

- (2011). E-education and Development of Innovative Economy in Russia. "Economic and Social Changes: Facts, Trends, Forecast", 4(16).

- (2011). The Influence of Information and Communication Technology on the Formation of Human Capital or Prospects for the Establishment of an Information Society in the Russian Federation. "National Interest: Priorities and Security", 41(134).

- (2012). Attitude of Young People to Information and Communication Technology, Health, and Healthy Lifestyle (based on the survey conducted among students in Kolomna and Lublin). "Population", 4(58).

- (2013). Negative Aspects of Information Society. “Economic Magazine”, 4(32).

(2014). Development of Internet Technology and Googlization of Mind of Young People. "National Interest: Priorities and Security", 3(240).

— (2014). The importance of the system of primary professional education for Russia's innovative economy. "Russian Education and Society", 56(5).

Mohamud, A. (2010). Internet Usage in the World. [access: 05.05.2021]. Access on the internet: www.comscore.com/Press_Events/Press_Releases/2010/10/Russia_Has_Most_Engaged_ Social_Networking_Audience_Worldwide

Sergeeva, Y. (2020). All Internet Statistics for 2020 - Russian and Global Figures and Trends [access: 05.05.2021]. Access on the internet: https://www.web-canape.ru/business/internet2020-globalnaya-statistika-i-trendy/

United Nations (2020). Two Thirds of the World's School-age Children Have no Internet Access at Home [access: 05.05.2021]. Access on the internet: https://news.un.org/ru/story/ 2020/12/1391572

Veselkin, E. A. (1976). The Concept of a Social Network in British Social Anthropology. Foreign Anthropology Concepts.

DOI: $10.7862 /$ rz.2021.hss.33

The text was submitted to the editorial office: August 2021.

The text was accepted for publication: December 2021. 
